DOI: $10.17805 /$ trudy.2015.4.5

\title{
РЕАЛИЗАЦИЯ ВОЛОНТЕРСКОГО ПОТЕНЦИАЛА СТУДЕНЧЕСКОЙ МОЛОДЕЖИ КАК ИТОГ СОЦИАЛЬНОГО ПРОЕКТИРОВАНИЯ
}

\author{
М. Г. Солнышкина \\ (Московский гуманитарный университет)
}

\begin{abstract}
Аннотация: В статье показана роль социального проектирования в привлечении молодежи к добровольчеству. В рамках предпроектной диагностики проведено исследование волонтерского потенцииала студенческой молодежи, выделены организационный и личностный уровни реализации волонтерского потенциала.
\end{abstract}

Ключевые слова: молодежное социальное проектирование, дети с ограниченными возможностями, социальный проект, волонтеры, студенческая молодежь.

\section{IMPLEMENTATION OF STUDENTS' VOLUNTEER CAPABILITY}

\author{
M. G. Solnyshkina \\ (Moscow University for the Humanities)
}

Abstract: The article shows the role of social engineering in promoting volunteering among the young. As part of pre-project diagnostic, we have studied volunteering capability of our students, looking at the organizational and personal levels of its implementation.

Keywords: youth social engineering, children with disabilities, social project, volunteers, student youth.

Стратегия государственной молодежной политики в РФ до 2016 г. в качестве приоритетного направления имеет включение в полноценную жизнь молодых людей, испытывающих проблемы с интеграцией в обществе (Государственная молодежная политика ... , 2013). Для реализации данного направления Стратегии государственной молодежной политики поставлена задача развития волонтерской деятельности молодежи; реализуется Федеральный проект «Шаг навстречу» по развитию толерантного отношения к людям, ограниченным в возможностях самореализации в обществе: инвалидам и детям-сиротам, относящимся к группе риска 
(Дивицына, 2008).

Молодежное добровольчество - это не только важный ресурс становления личности добровольца, но и мощный общественный инструмент социализации личности (Социология молодежи, 2008: 442).

В качестве одного из показателей эффективности добровольческой деятельности (в аспекте взаимодействия органов исполнительной власти субъектов Российской Федерации с добровольцами) принят целевой индикатор «доля молодых людей, принимающих участие в добровольческой деятельности, в общем числе молодежи (в процентах)» (Гневашева, Фальковская, 2011: 54). В 2015 г. доля молодых добровольцев, к которым в России относятся молодые люди от 14 до 30 лет, должна составлять не менее $18 \%$ от общего количества молодежи.

Взаимодействие молодежных волонтерских организаций с детьми группы риска (понятие рассматривается в контексте факторов, оказывающих негативное влияние на ребенка) реализуется в рамках системы социальных служб: детских домах, домах-интернатах, специальных школах для детей с ограниченными возможностями, в медико-социальных учреждениях. За 20 лет существования системы социальной защиты в России сложилась сеть учреждений, как на региональном, так и на федеральном уровнях, оказывающих социальных услуги детям группы риска с целью социальной помощи и поддержки (Топчий, 2012). Российская законодательная база в области защиты детей группы риска сформировалась под влиянием международных законодательных актов и составляет в настоящее время более 300 нормативных документов, затрагивающих все сферы жизнедеятельности детей: федеральные законы, указы президента, постановления правительства Российской Федерации. Институционализация данного направления социальной работы сопровождалась развитием волонтерских организаций, объектами деятельности которых являются дети группы риска. Вместе с тем, формирование и реализация волонтерского потенциала происходят неравномерно в региональном пространстве, не все социальные группы молодежи мотивированы к волонтерской деятельности в отношении детей группы риска в системе социальных служб, что снижает как эффективность государственной молодежной политики, так и успешность социализации молодежи.

\section{Предпроектная диагностика волонтерского потенциала студенческой молодежи}

Показателем волонтерского потенциала студенческой молодежи является уровень социальной активности и желание участвовать в добровольческой деятельности. С целью предпроектной диагностики волонтерского потенциала студенческой молодежи в университете природы, 
общества и человека «Дубна» в ноябре-декабре 2014 г. проведено анкетирование студентов для изучения ценностных ориентаций потенциальных волонтеров, степени информированности о волонтерском движении, предпочтения областей волонтерской деятельности ${ }^{1}$. В анкетировании приняли участие 200 студентов университета (112 девушек и 88 юношей в возрасте от 17 до 23 лет, что отражает социально-демографические характеристики студентов данного вуза).
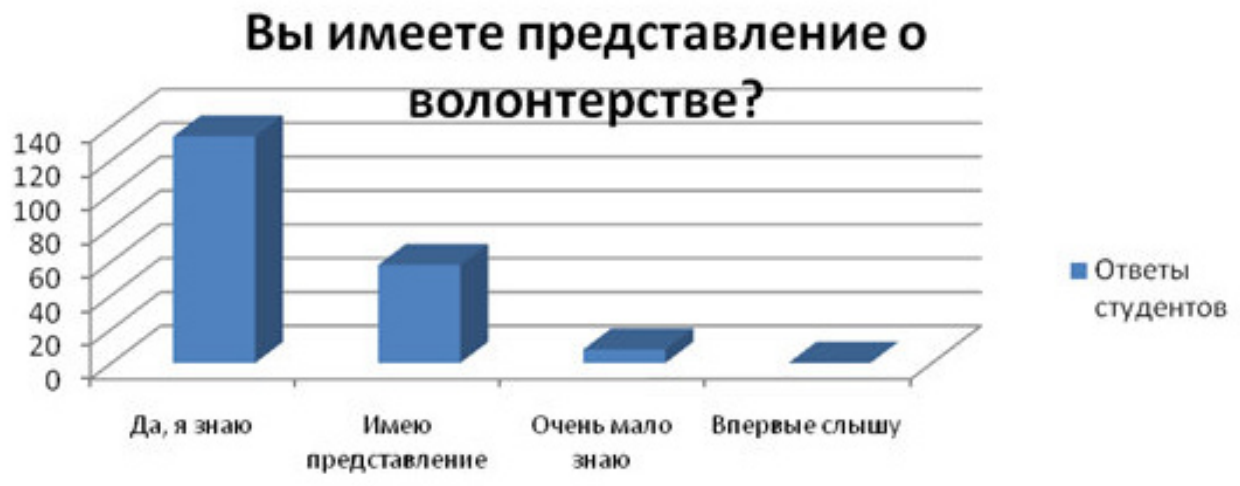
Рис. 1. Резуль- таты исследования осведомленности о волонтерской дея- тельности.

По результатам исследования выявлена высокая осведомленность о волонтерской деятельности: 67\% студентов знают о социальной значимости волонтерства, 29\% имеют общее представление о данном социальном явлении (см. рис. 1).

40\% студентов изъявили желание участвовать в деятельности волонтерской организации, при этом оно обусловлено совпадением направленности мероприятий интересам личности (48,5\%), наличием свободного времени (10\%). 1,5\% опрошенных не готовы участвовать в волонтерской деятельности. Выраженное желание оказать помощь возникает у студен-

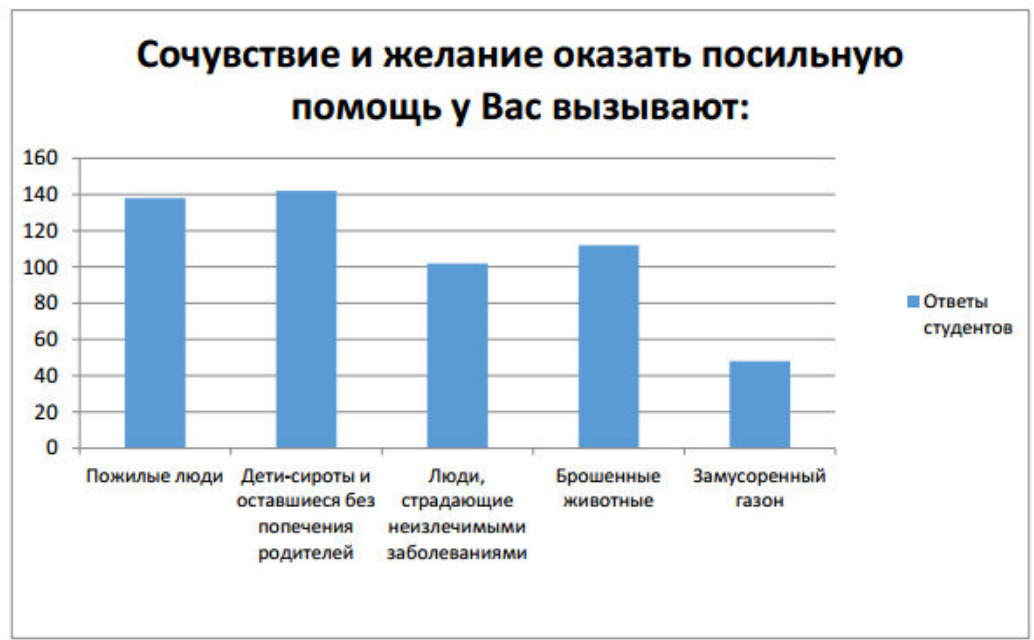
тов в отношении детейсирот и пожилых людей (см. рис. 2).

Рис. 2. Результаты исследования привлекательности объектов волонтерской деятельности

Из предложенных областей добровольческой деятельности на высоком уровне привлекательности находятся социокультурная и досуговая (дети и подростки), сбор подарков и средств и помощь в приютах для бездомных животных (см. рис. 3). Наибольшее желание помочь вызывают дети-сироты и дети, оставшиеся 


\section{Какая область волонтерской деятельности кажется Вам самой привлекательной?}

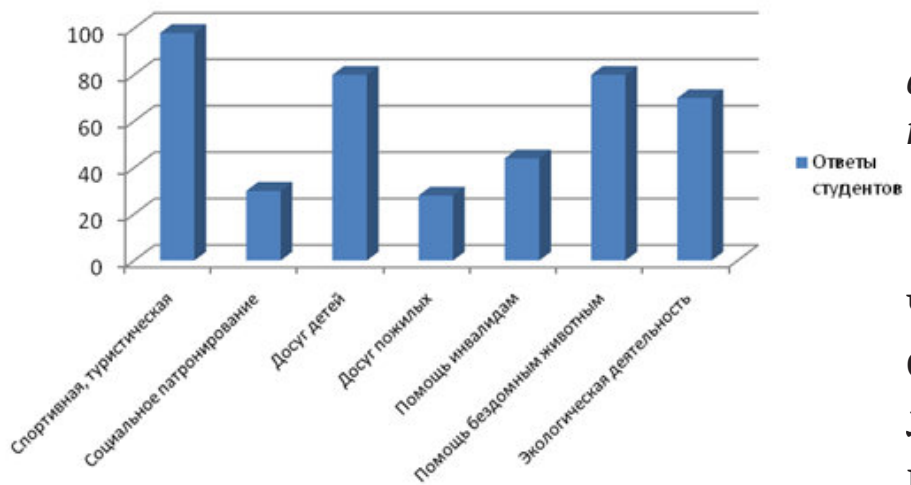

без попечения родителей и пожилые люди.

Рис. 3. Распределение областей волонтерской деятельности по степени привлекательности

Исследование показало, что студенческая молодежь достаточно мотивирована на волонтерскую деятельность в отношении детей группы риска в системе социальных служб, но

для реализации волонтерского потенциала молодежи необходимы специальные социальные механизмы.

\section{Социально-проектные механизмы реализации волонтерского потенциала студенческой молодежи}

Реализация волонтерского потенциала студенческой молодежи имеет проектную основу и ориентирована на достижение конечных целей социальных проектов как способов изменения социальной реальности и решения проблем детей группы риска (Луков, Солнышкина, 2011: 130). Реализация волонтерского потенциала студенческой молодежи осуществлялась в форме социального проектирования с целью развития творческих способностей и создания условий для успешной социализации детей-инвалидов и детей из кризисных семей в социальном учреждении «Бригантина» (проект «Ярмарка талантов»²) и соответствовала приоритетам государственной молодежной политики интеграции в общество молодежи, оказавшейся в трудной жизненной ситуации (Луков, 2010).

Цель проекта - развитие творческого потенциала детей из кризисных семей и детей с ограниченными возможностями. Целевой группой проекта являются дети с ограниченными возможностями и дети из кризисных семей в возрасте 7-10 лет.

Формой реализации проекта является проведение мастер-классов: «Рисование мыльными пузырями», «Граттаж», «Аппликация из ткани», «Фоторамка из фетра» и организация выставки «Ярмарка талантов».

Задачи социального проекта:

- Стимулирование познавательного интереса детей из кризисных семей и детей с ограниченными возможностями как условие их дальнейшего развития;

- Развитие способности самостоятельно мыслить, принимать творческие решения; 
•Повышение самооценки детей;

-Интеграция в общество.

В контексте ресурсов данной акции молодежное социальное проектирование рассматривается как инновационный ресурс, создающий дополнительные возможности решения проблем детей-инвалидов и интеграции их в современное общество (Солнышкина, 2014).

Реализация проекта по социокультурной реабилитации детей из кризисных семей способствовала развитию добровольческой деятельности, но, одновременно, потребовала ее более четкой структуризации и организации. По итогам реализации данного проекта разработан проект создания волонтерской организации «Доброе сердце», сформированной на базе кафедры социальной работы Международного университета природы, общества и человека «Дубна» и ориентированной под нужды реабилитационного центра «Бригантина». Проект предполагает формирование актива отряда, обучение добровольческой деятельности, реализацию волонтерских мероприятий и акций, сопровождение реабилитационных мероприятий с учетом особенностей детей${ }^{3}$.

\section{Типологизация социального проекта:}

по характеру проектируемых изменений - относительная инновация;

по направлениям деятельности - социально-реабилитационный добровольческий проект;

по срокам реализации - среднесрочный;

по особенностям финансирования - смешанное финансирование;

по масштабам - малый проект.

Краткое содержание проекта. Планируется создание волонтерского отряда как благотворительной общественной организации и использование волонтерского ресурса при групповых занятиях с детьми с ограниченными возможностями, при подготовке к открытым мероприятиям, играм, конкурсам, в деятельности ассистентами интегративных консультантов при оказании реабилитационных услуг на дому. Использование волонтерского ресурса позволит повысить адресность и качество услуг, сделать их более разнообразными. Волонтерское сопровождение приведет к частичной разгрузке специалистов, предупредит их переутомление и эмоциональное выгорание. Кроме того, создание волонтерского отряда - это новая стадия отношений кафедры социальной работы и организаций города Дубна, что поможет сформировать необходимые компетенции выпускников, их гражданскую позицию, повысит готовность к профессиональной деятельности.

\section{Предполагаемые виды работ:}

1) Разработка программы волонтерской деятельности;

2) Подбор и обучение волонтеров;

3) Создание сайта волонтерской организации; 
4) Организация акций и интеграция их в деятельность Центра;

5) Подведение итогов.

Возможные пути финансирования проекта.

Предполагается смешанное финансирование проекта: часть средств может быть выделена Управлением социальной защиты населения г. Дубна, муниципалитетом, также предусмотрена спонсорская помощь организаций города, Попечительского совета Центра «Бригантина».

Отчет о потраченных средствах будет представлен на сайте волонтерского отряда.

Целевые группы социального проекта:

-Дети с ограниченными возможностями;

-Дети из кризисных семей (отдел участковой социальной службы).

Проблема, на разрешение которой направлен социальный проект. Недостаточность ресурсной базы социально-реабилитационной помощи при осуществлении групповых социально-психо-реабилитационных и коррекционных мероприятий и социальном обслуживании на дому по инновационным технологиям.

\section{Содержание социального проекта.}

Цель проекта - формирование и реализация потенциала добровольчества как движущей силы социализации детей, организация волонтерского сопровождения социально-реабилитационных, психокоррекционных услуг в реабилитационном центре «Бригантина» и при социальном обслуживании на дому.

\section{Задачи проекта:}

1. Волонтерское сопровождение спортивных, музыкальных и др. групповых занятий с детьми;

2. Социокультурная реабилитация детей совместно с общественными организациями в режиме социального партнерства, привлечение волонтеров из числа взрослого населения города;

3. Развитие досуга детей с ограниченными возможностями, детей из кризисных семей, интеграционная деятельность на дому;

4. Организационно-методическая поддержка реабилитации детейинвалидов с привлечением профессорско-преподавательского состава кафедры социальной работы.

Программа деятельности волонтерской организации формируется в соответствии с целями социально-реабилитационного центра «Бригантина» и миссией волонтерского отряда по формированию позитивных установок на добровольческую деятельность. В центре «Бригантина» разрабатываются инновационные мероприятия, способствующие успешной социализации и реабилитации детей, открываются новые направления интегративно-консультационной работы на дому. Студенты кафедры «Социальная работа» будут осуществлять сопроводительную деятель- 
ность в отделении психолого-педагогической помощи реабилитационного Центра (групповые мероприятия по игротерапии, музыкотерапии, арт-терапии, подвижным играм, компьютерные занятия, проведение праздничных мероприятий и т. д.). Совместно с отделением участковой социальной службы будет осуществляться сопровождение детей из неблагополучных семей и деятельность ассистентами интегративных консультантов на дому.

Планируется проведение следующих мероприятий: «Волонтеры -детям Дубны»; «Ограниченные возможности - неограниченные таланты», а также мастер-классы по направлениям: «Изобразительное искусство», «Аппликация», «Поделки из природных материалов», «Изготовление масок из папье-маше». Для организационно-методической поддержки реабилитации детей-инвалидов будут созданы методические папки, включающие разработки по реабилитации детей-инвалидов научного, методического, социально-технологического характера.

\section{Организационные механизмы реализации волонтерского потенциала студенческой молодежи}

Проведенная исследовательская работа, проектная деятельность, а также неоднократные посещения «Единого дня открытых дверей» по социальному обслуживанию детей-инвалидов на базе Дубненского реабилитационного центра «Бригантина» создали необходимые условия для реализации социального проекта «Доброе сердце».

На организационном собрании студентов определена структура волонтерской организации (президент отряда, секретарь-менеджер, ответственные менеджеры по каждому направлению волонтерской деятельности, ответственные за методическое обеспечение). Также решено привлечь к волонтерской деятельности студентов первого курса в качестве рядовых членов отряда, запросить у Дубненского реабилитационного центра для детей и подростков «Бригантина» перечень социальных мероприятий, в которых необходимо участие волонтеров.

«Дети группы риска» - понятие, включающее в себя достаточно широкий круг детей и подростков, нуждающихся в социальной поддержке государства (Кокоренко, 2011: 34). В связи с этим волонтерская деятельность молодежи в отношении детей группы риска представляет собой комплекс мероприятий, направленных на их успешную социализацию, ресоциализацию и адаптацию (Ковалева, 2011). Программа деятельности волонтерского отряда «Доброе сердце» на 2015 г. включает проведение следующих комплексных социальных мероприятий: «День защиты детей», «День знаний», «День матери», «День инвалида», «Новый год», а также участие в благотворительных акциях «Школьник-2015», «Согреем детские сердца» и 
«Новогодняя мечта». Перед мероприятиями проводятся мастер-классы, в летний период волонтеры сопровождают детей на занятия.

Таким образом, социальное проектирование способствует увеличению молодежных добровольческих ресурсов. Развитие у студентов навыков проектной деятельности используется в реализации проектов в интересах детей группы риска. В результате молодежного социального проектирования формируется и реализуется потенциал добровольчества как движущая сила преодоления социальной изолированности, создания интегративной среды и условий для улучшения жизни детей-инвалидов и семей, воспитывающих детей с ограниченными возможностями.

\section{СПИСОК ЛИТЕРАТУРЫ}

Государственная молодежная политика: российская и мировая практика реализации в обществе инновационного потенциала новых поколений (2013) / под общ. ред. Вал. А. Лукова. М. : Изд-во Моск. гуманит. ун-та. 718 с.

Гневашева, В. А., Фальковская, К. И. (2011) Эффективность молодежной политики: проблема определения критериев (результаты экспертного опроса) // Знание. Понимание. Умение. № 6. С. 70-74.

Дивицына, Н. Ф. (2008) Социальная работа с детьми группы риска : краткий курс лекций для вузов. М. : Владос. 351 с.

Ковалева, А. И. (2011) Общество и личность : лекции по социологии. М. : Изд-во Москов. гуманит. ун-та. 204 с.

Кокоренко, В. Л. (2011) Социальная работа с детьми и подростками : учебное пособие. М. : Академия. 256 с.

Луков, В. А. (2010) Социальное проектирование. 9-е изд. М. : Изд-во Моск. гуманит. ун-та. 286 с.

Луков, В. А., Солнышкина, М. Г. (2011) Новые идеи в социологии управления. М. : Изд-во Московского гуманитарного университета. 192 с.

Солнышкина, М. Г. (2014) Молодежное социальное проектирование как инновационный ресурс Всероссийской акции «Добровольцы-детям» // Гуманитарная среда как условие формирования общекультурной компетентности : сборник статей. М. : Изд-во Моск. гуманит. ун-та. 182 с. С. 151-155.

Социология молодежи (2008) : энциклопедический словарь / отв. ред. Ю. А. Зубок, В. И. Чупров. М. : Academia. 606 с.

Топчий, Л. В. (2012) Социальное обслуживание населения: ценности, теория, практика. М. : Изд-во РГСУ. 156 с.

Солнышкина Марина Георгиевна - доктор социологических наук, профессор, профессор кафедры социологии Московского гуманитарного университета. Адрес: 111395, Россия, г. Москва, ул. Юности, д. 5. Тел.: +7 (499) 374-60-21. Эл. адрес: solny2001@mail.ru 
Solnyshkina Marina Georgievna, Doctor of Sociology, Professor, Department of sociology, Moscow University for the Humanities. Postal address: 5 Yunosti St., 111395 Moscow, Russian Federation. Tel.: +7 (499) 37460-21.E-mail: solny2001@mail.ru

\section{ПРИМЕЧАНИЯ}

${ }^{1}$ Анкетирование проводилось М. Н. Китаевой, студенткой 5 курса кафедры социальной работы Университета «Дубна».

${ }^{2}$ Автор проекта - К. С. Мачалкина, студентка 4 курса кафедры социальной работы Университета «Дубна»; руководитель проекта - М. Г. Солнышкина.

${ }^{3}$ Автор проекта - М. Н. Китаева, студентка 4 курса кафедры социальной работы Университета Дубна; руководитель проекта - М. Г. Солнышкина. 